\title{
The EMR-rural project: key techniques and devices development for rural environmental monitoring and remediation in China
}

\author{
Zhongli Chen ${ }^{1}$ (D), Ying Shao ${ }^{1}$, Miao He ${ }^{2}$, Jialiang Liang ${ }^{1}$, Yanxue Jiang ${ }^{1}$, Yayi Wang ${ }^{3}$, Minghua Zhou ${ }^{4}$, \\ Zongqiang Gong ${ }^{5}$, Xiaohong Zhou ${ }^{2}$, Fang Fang ${ }^{1}$ and Jinsong Guo ${ }^{1 *}$
}

\begin{abstract}
Rural development, as one of the biggest challenges facing human beings recently, has attracted widely attention in the world, among which rural environment protection is essential for sustainable development. In response to the call to build "green livable villages", the environmental monitoring and remediation in rural project (EMR-rural project) is launched. EMR-rural (2019 to 2022) is funded by the Ministry of Science and Technology of the People's Republic of China (MOST). The project aims to develop key techniques and devices for contamination classification, risk assessment, pollution sources tracing and environmental remediation with regard to soil, underground and surface water quality in rural area. To this end, a new generation of physical, chemical and biological tools is integrated with intelligent management platform. The project follows a problem-oriented approach by in situ investigation, lab/pilot-scale mechanism exploration and field determination. EMR-rural takes advantage of the access to the applicable techniques and devices to investigate and to restore soil and water pollution in river network areas, mountainous areas as well as cold areas of China.
\end{abstract}

\section{Introduction}

Rural, as a supplier of food and natural resources, plays key roles for the economic well-being of people living in rural and urban areas [1]. While along with the urbanization and industrialization, rural communities face increasing pressures and risks from agricultural livelihoods, climate change, new technologies, commodity prices, environmental regulations and economic conditions [2,3]. The rural development is hence a hot topic and difficult issue for human beings, since the increasing regional imbalances between urban and rural in terms of population change, economic development,

*Correspondence: guo0768@cqu.edu.cn

${ }^{1}$ Key Laboratory of the Three Gorges Reservoir Region's Eco-Environment, College of Environment and Ecology, Chongqing University,

Chongqing 400030, People's Republic of China

Full list of author information is available at the end of the article access to services, and social outcomes [4]. Strategies to deal with rural development have aroused widely concerns. Remote regions are taken into consideration, where targeted differentiated approaches are provided [5, 6]. For instance, bottom-up approach, participatory rural appraisal (PRA), rapid rural appraisal (RRA) and working with people (WWP) have been developed and implemented [7]. Agencies and programs, such as International Institute of Rural Reconstruction (IIRR), Technical Center for Agricultural and Rural Cooperation (TCAR), United States Department of Agriculture (USDA) Office of Rural Development and European Network for Rural Development (ENRD) have been established to explore land-intensive natural resources such as agriculture and forestry [8], among which management of natural resources and preservation of ecological balance are perceived today as essential elements of rural 
development. Concerns have grown over the impact of intensive human activities on the rural environment [9]. Consequently, environmental departments are intended not only to reduce the environmental damages resulting from uncontrolled urbanization and industrialization, but also to address ecosystemic degradation in the countryside [10]. The concept of sustainable rural development which characterized by emphasis on natural, landscape and cultural resources protecting and preserving was hence developed $[11,12]$.

In this context, the Ministry of Science and Technology of the People's Republic of China (MOST) launched a series of projects, namely "green livable village program", to improve the rural living environment and to promote the coordination of agricultural production, living condition and ecological conservation. The program was launched under the direction of the rural vitalization strategy. To build green livable villages, key technologies in the fields of rural cleaning, environmental health, town and village planning, livable housing, green construction materials and clean energy are desired. Thus, platforms on basic research, smart village and ecological construction will be built to promote the construction and development of "green livable villages". Among which rural environment is essential for sustainable rural construction, since a good quality of rural environment can promote sustainable construction [13], while degraded environment may bring negative effects on rural construction [14]. Recently, under pressure from economy and society, more and more synthetic chemicals, such as pesticides, fertilizers, and pharmaceutical and personal care products (PPCPs), are utilized for agriculture, stock farming and livelihoods to support rural development [15-17]. As a result, a large amount of those chemicals are inevitably released into rural areas, which caused serious damages for rural environment and even human health [18]. To address these problems, environmental monitoring and restoration, which are often designed to establish the current environmental status or the trends in environmental parameters, are vital for regulatory agencies [6, 14, 19-21]. Thus, rural environment monitoring and remediation, as one of the major requirements for rural sustainable development, was set as one of the projects in the "green livable village program" for the purpose of healthy environments.

The environment monitoring and remediation in rural (EMR-rural) project is a 38-month project (2019-2022). The EMR-rural consortium consists of 10 partners from different areas of China, including six universities (Chongqing University, Tsinghua University, Tongji University, Central South University, Huazhong Agricultural University and Donghua University), three research institutes (Institute of Applied Ecology, CAS; Institute of
Mountain Hazards and Environment, CAS; Academy of Agricultural Planning and Engineering, MARA) and an instrumental manufacturer (Focused Photonics (Hangzhou), Inc.). EMR-rural will focus on the development of key techniques for (1) analysis of the characteristics of pollutant transportation and transformation under the interference of residents activities; (2) restoration of the contaminated surface water and groundwater bodies to meet the requirements of water environment improvements in river network areas; (3) coordinately restoration of soil and water in mountain areas to challenge the technical difficulties in soil interflow pollution treatments, (4) polluted soil and water remediation during freezing and thawing to support the effectively environment management in cold region; (5) development of rural applicable instruments or sensors to trace pollutant sources, identify key pollutants that induced multi-toxic effects and assess unknown/unexpected risks, and finally (6) establishing an integrated simple, economical and applicable rural environmental monitoring and early-warning platform.

\section{Current research status of environmental monitoring and remediation}

Studies on environmental pollution were verified by searching in Web of Science. The environmental pollution-related terms were set as keywords in topic/databases, listed according to their frequency of occurrence. The search period was limited between 2010 and 2019, and the results are summarized in Table 1 . In recent decade, rural environmental monitoring and restoration have attracted extensively attention worldwide [21, 22]. Among the research areas, traditional pollutants such as nitrogen, phosphorus, heavy metals, pesticides, and emerging contaminates polychlorinated biphenyls (PCBs), polycyclic aromatic hydrocarbons (PAHs) are still major concerns [23-25]. The research topics have turned from specific pollutants removal and their environmental behaviors to the relationship between pollutants and ecological and health risk [26, 27]. However, studies regarding emerging pollutants are still not adequate since their increasing variety and quantity $[28,29]$.

The inadequate studies and the existence of unknown/unexpected risks are human major challenges. In the current study, we defined the unknown/ unexpected risks as (1) pollutants that have not yet been identified/detected in environments, and their toxic effects to biota and risks are hence unknown; (2) chemicals which were already detected in environments, but their environmental/ecological risks are still unknown and (3) complex environmental mixtures which composed identified and unidentified chemicals, while studies on their fate/risks are still insufficient. 
Table 1 Records for the environmental monitoring and restoration terms, filtered by publication period (2010 to 2019), listed according to the frequency of occurrence

\begin{tabular}{|c|c|c|c|c|c|c|c|c|}
\hline \multicolumn{3}{|c|}{ Frequency of key words } & \multicolumn{6}{|c|}{ Burst of key words } \\
\hline $\begin{array}{l}\text { Rank } \\
\text { of frequency }\end{array}$ & Key words & $\begin{array}{l}\text { No. } \\
\text { of frequency }\end{array}$ & $\begin{array}{l}\text { Time } \\
\text { sequence }\end{array}$ & Key words & Burst intensity & Start & End & 2010-2019 \\
\hline 1 & Heavy metals & 324 & 1 & Risk factor & 3.15 & 2016 & 2019 & مس \\
\hline 2 & Drinking water & 304 & 2 & Health risk & 16.09 & 2016 & 2019 & سمس \\
\hline 3 & Pollution & 283 & 3 & PCBs & 2.88 & 2016 & 2017 & 2 \\
\hline 4 & Exposure & 275 & 4 & Land use & 11.00 & 2016 & 2017 & - 2- \\
\hline 5 & Soil & 239 & 5 & Constructed wetland & 10.41 & 2015 & 2016 & 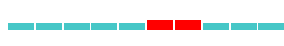 \\
\hline 6 & Nitrogen & 214 & 6 & Adsorption & 7.50 & 2015 & 2016 & - \\
\hline 7 & Underground water & 203 & 7 & River & 7.46 & 2014 & 2015 & - \\
\hline 8 & Air pollution & 189 & 8 & Wastewater & 5.40 & 2014 & 2015 & - \\
\hline 9 & Particulate matter & 188 & 9 & Form & 7.58 & 2014 & 2015 & \\
\hline 10 & Water & 180 & 10 & $\mathrm{PAHs}$ & 6.97 & 2012 & 2014 & \\
\hline 11 & Health & 165 & 11 & PM2.5 & 11.98 & 2012 & 2013 & \\
\hline 12 & Discharge & 154 & 12 & PCBs & 10.05 & 2011 & 2012 & 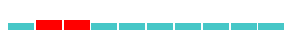 \\
\hline 13 & Arsenic & 150 & 13 & OCPs & 3.50 & 2011 & 2012 & - \\
\hline 14 & Children & 150 & 14 & Particulate matter & 9.43 & 2010 & 2012 & سعس \\
\hline 15 & Microelement & 147 & 15 & Air & 9.35 & 2010 & 2011 & - \\
\hline 16 & PCBs & 145 & 16 & Rural area & 4.57 & 2010 & 2011 & r- \\
\hline 17 & Pesticides & 143 & 17 & Population & 2.42 & 2010 & 2011 & - \\
\hline
\end{tabular}

As shown in Fig. 1, researches on pollution control and remediation concentrated in river network areas, whereas the studies in mountainous rural regions and cold areas are rare, in particular for the soil interflow pollution. When it involves unknown/unexpected environmental/ecological risk, the relevant research data are even fewer, regardless of in river network areas, mountainous regimes or cold areas [30]. Studies on environment monitoring and remediation to support effective environmental management in rural area are huge challenges nowadays [27, 31].

In a general term, the technology development trends of environmental monitoring and remediation are as follows: (1) pollutant monitoring has been extending from traditional pollutants to emerging pollutants [32, 33]; (2) specific focus is given to restoration technologies and devices, and (3) integrated technologies are desired [34, 35]. These trends call us to improve the knowledge on the mechanisms of pollutants transportation and transformation in different rural environmental processes. Effective environment monitoring and remediation rely on accurate data and cognition [36], which are the fundamental of technologies and equipment innovation for combined restoration of water and soil. In addition, the economic, intelligent, reliable, practicable monitoring and remediation techniques and devices, such as online intelligent monitoring, and early-warning platform are desired for rural environment management.

\section{Objectives}

The EMR-rural project supports the overall aim of developing key techniques and devices for rural environmental monitoring and remediation toward the construction of "green livable village". The proposed conceptual framework addresses major challenges of rural environment monitoring and renovation. EMR-rural focuses on three research aspects: (1) techniques and devices for pollution classification and risk assessment that are suitable for the characteristics of pollutant transportation/transformation and combined pollution during different biogeochemical processes; (2) environmental remediation techniques and devices that are suitable for the processes of frequent underground/surface water interaction (U/S interaction), alternation of drying and wetting (D/W alternation), and freezing-thawing phase transition (F/T transition) and (3) early-warning platforms and networkmonitoring techniques for rural environments.

The U/S interaction, D/W alternation and F/T transition are typical rural natural environmental processes in river network regions, mountainous regions and cold regions, respectively. These biogeochemical processes play important roles for pollutants transportation, transformation, and source-to-sink patterns of pollutants, which may result in variations of hazards in rural environments. EMR-rural intends to explore a technical system for pollution monitoring, classification and risk assessment in rural environments through probing the 


\begin{tabular}{|c|c|c|c|c|c|c|c|c|c|c|c|}
\hline Key words & $\begin{array}{l}\text { Total frequency } \\
(2010-2019)\end{array}$ & 2010 & 2011 & 2012 & 2013 & 2014 & 2015 & 2016 & 2017 & 2018 & 2019 \\
\hline (River network) or (Delta) and Pollution source and Rural & 178 & 7 & 14 & 12 & 9 & 20 & 22 & 19 & 28 & 28 & 19 \\
\hline (River network) or (Delta) and (Sustainable) or (Sustainability) & 145 & 9 & 7 & 13 & 8 & 13 & 16 & 25 & 19 & 28 & 7 \\
\hline $\begin{array}{l}\text { (River network) or (Delta) and (Reme diation) or (Degradation) } \\
\text { or (Occurrence) or (Restoration) and Rural }\end{array}$ & 135 & 4 & 9 & 12 & 11 & 13 & 11 & 19 & 13 & 36 & 7 \\
\hline (Plateau or Highland) and (Unknown risk) or (Unexpected risk) & 108 & 6 & 6 & 6 & 12 & 12 & 11 & 13 & 18 & 11 & 13 \\
\hline $\begin{array}{l}\text { (Cold region) or (Plateau) and (Sustainable) or } \\
\text { (Sustainability) and Rural }\end{array}$ & 83 & 3 & 5 & 3 & 6 & 9 & 10 & 8 & 9 & 18 & 12 \\
\hline (Plateau or Highland) and Pollution control & 83 & 3 & 2 & 3 & 9 & 6 & 12 & 9 & 11 & 17 & 11 \\
\hline (River network) or (Delta) and Pollution control and Rural & 78 & 2 & 3 & 5 & 5 & 4 & 9 & 10 & 13 & 17 & 10 \\
\hline $\begin{array}{l}\text { (River network) or (Delta) and (Environmental risk) or } \\
\text { (Ecological risk) and Rural }\end{array}$ & 68 & 4 & 3 & 6 & 9 & 4 & 6 & 10 & 7 & 12 & 7 \\
\hline $\begin{array}{l}\text { (River network) or (Delta) and (Unknown risk) or (Unexpected } \\
\text { risk) }\end{array}$ & 65 & 3 & 2 & 3 & 7 & 6 & 4 & 10 & 7 & 16 & 7 \\
\hline $\begin{array}{l}\text { (Cold region) or (Plateau) and (Remediation) or } \\
\text { (Degradation) or (Occurrence) or (Restoration) and Rural }\end{array}$ & 61 & 5 & 7 & 0 & 9 & 5 & 5 & 7 & 8 & 7 & 8 \\
\hline $\begin{array}{l}\text { Interflow and (Remadiation) or (Degradation) or (Occurrence) } \\
\text { or (Restoration) }\end{array}$ & 38 & 5 & 2 & 6 & 1 & 5 & 8 & 3 & 2 & 4 & 2 \\
\hline (Cold region) or (Plateau) and (Pollution source) and Rural & 36 & 1 & 3 & 4 & 2 & 6 & 3 & 2 & 9 & 2 & 4 \\
\hline $\begin{array}{l}\text { (Cold region) or (Plateau) and (Sustainable) or } \\
\text { (Sustainability) and Rural }\end{array}$ & 28 & 0 & 3 & 1 & 1 & 4 & 5 & 6 & 3 & 2 & 3 \\
\hline $\begin{array}{l}\text { (Cold region) or (Plateau) and (Unknown risk) or } \\
\text { (Unexpected risk) }\end{array}$ & 27 & 1 & 4 & 4 & 1 & 2 & 3 & 0 & 5 & 4 & 3 \\
\hline $\begin{array}{l}\text { (Cold region) or (Plateau) and (Environmental risk) or } \\
\text { (Ecological risk) and Rural }\end{array}$ & 26 & 3 & 1 & 2 & 3 & 1 & 3 & 1 & 4 & 5 & 3 \\
\hline Interflow and Pollution & 24 & 1 & 2 & 2 & 3 & 2 & 3 & 3 & 4 & 1 & 3 \\
\hline $\begin{array}{l}\text { (Unknown risk) or (Unexpected risk) and (Sustainable) or } \\
\text { (Sustainability) and Rural }\end{array}$ & 15 & 0 & 0 & 1 & 0 & 3 & 2 & 3 & 2 & 2 & 2 \\
\hline (Cold region) or (Plateau) and (Pollution Control) and Rural & 12 & 1 & 1 & 2 & 0 & 1 & 2 & 1 & 1 & 2 & 1 \\
\hline Interflow and (Pollution source) & 12 & 1 & 1 & 1 & 2 & 0 & 1 & 2 & 2 & 0 & 2 \\
\hline (Cold region) or (Plateau) and (Pollution source) and Rural & 10 & 0 & 4 & 0 & 0 & 1 & 1 & 1 & 1 & 1 & 1 \\
\hline Interflow and (Pollution control) & 9 & 0 & 0 & 0 & 3 & 0 & 2 & 1 & 1 & 0 & 2 \\
\hline $\begin{array}{l}\text { (Cold region) or (Plateau) and (Environmental risk) or } \\
\text { (Ecological risk) and Rural }\end{array}$ & 7 & 0 & 0 & 2 & 1 & 0 & 0 & 2 & 1 & 1 & 0 \\
\hline (Interflow) and (Sustainable) or (Sustainability) & 7 & 0 & 1 & 0 & 0 & 0 & 3 & 0 & 1 & 1 & 1 \\
\hline Interflow and Rural & 2 & 1 & 0 & 0 & 0 & 0 & 0 & 1 & 0 & 0 & 0 \\
\hline $\begin{array}{l}\text { (Cold region) or (Plateau) and (Unknown risk) or (Unexpected } \\
\text { risk) and Rural }\end{array}$ & 2 & 0 & 0 & 0 & 0 & 0 & 1 & 0 & 0 & 0 & 1 \\
\hline Interflow and (Environmental risk) or (Ecological risk) & 2 & 0 & 0 & 1 & 0 & 0 & 0 & 0 & 0 & 1 & 0 \\
\hline Interflow and (Unknown risk) or (Unexpected risk) & 0 & 0 & 0 & 0 & 0 & 0 & 0 & 0 & 0 & 0 & 0 \\
\hline
\end{tabular}

Fig. 1 Heatmap for records of three typical environmental regions/processes, filtered by publication period (2010 to 2019)

dynamics, transformation mechanism of pollutants in various environmental media during different natural biogeochemical processes.

In view of the frequent $\mathrm{U} / \mathrm{S}$ interaction in river network regions, EMR-rural will first investigate the pollutants' characteristics in groundwater, surface water and soil. Based on these characteristics, remediation techniques, such as phytoremediation, microbiological remediation, zero-valent iron coupled biochar remediation and chemical stabilization will be regulated and optimized to combine restore water and soil effectively. Afterward, an integrated technical system will be created, assembling plant, microorganism and chemical stabilization for contamination remediation in river network areas.

In mountainous region, the interflow often accompanied by soil alternations between drying and wetting is one of key factors for pollutants' source-sink conversion. An ecological reactive barrier will be equipped with techniques of anaerobic ammonia oxidation, denitrification, nitrogen and phosphorus hyper-accumulators, and metallic passivator to remove pollutants. Besides, in consideration of scattered distribution of garbage in mountainous region, a simple landfill will be developed and applied to remediate soil and interflow in situ. 
$\mathrm{F} / \mathrm{T}$ transition is a common phenomenon in cold regions, which always induces redistribution of contamination in water and soil, and may affect the pollutants' transformation efficiency. The low activity of microorganism and its short action period at low temperature challenge on pollution degradation when suffering freezing-thawing stress. EMR-rural will screen specific microorganisms and antifreeze materials, and simultaneously integrate temperature control module to combat multiple disturbance of low temperature. In particular, livestock farms, as typically contaminated places with complex pollutants in rural, will be coupled with bioremediation technology in cold environments.

To provide convenient measurement for pollution monitoring and effective implementation for water/soil remediation in complex rural environments, economical, easy-to-handle and applicable instruments are indispensable parts. EMR-rural plans to exploit an in situ sensor and a dual-mode equipment to trace pollutant sources, a nuclear receptor-based biosensor to ascertain risks, an apparatus to rapid detect and identify heavy metals, and a portable instrument to investigate the acute toxicity of water. In regard to remediation facilities, EMR-rural intends to develop a device for surface water restoration, an implementor for heavy metals' detoxification, remediation equipment base on interactive fluidized biofilms' technology for interflow, and an integrative system for permafrost pollution in livestock farms.

Therefore, EMR-rural is structured into five subprojects, which will be set according to the workflow illustrated in Fig. 2. Sub-project 1 (SP1) will carry out the occurrence characteristics, ecological risk and fate of pollutants. SP2 focuses on comparative remediation techniques and equipment development for river network areas. In SP2, technologies for water-soil-integrated remediation will be explored by combining biological and chemical methods. SP3 will first quantify the transportation process and flux of pollutants. Then, the transformation mechanism of pollutant source-sink during $\mathrm{D} / \mathrm{W}$ alternations in soil interflow will be explored. Afterward, a simple landfill instrument equipped pollution control and water-soil remediation techniques will be implemented. A collaborative system for remediation of water-soil with characteristics of interflow will be finally constructed in SP3. SP4 pays close attention to the low activity of soil microorganisms in cold regions and the challenge of freezing-thawing stress imposed to polluted environments. The major work of SP5 is about key

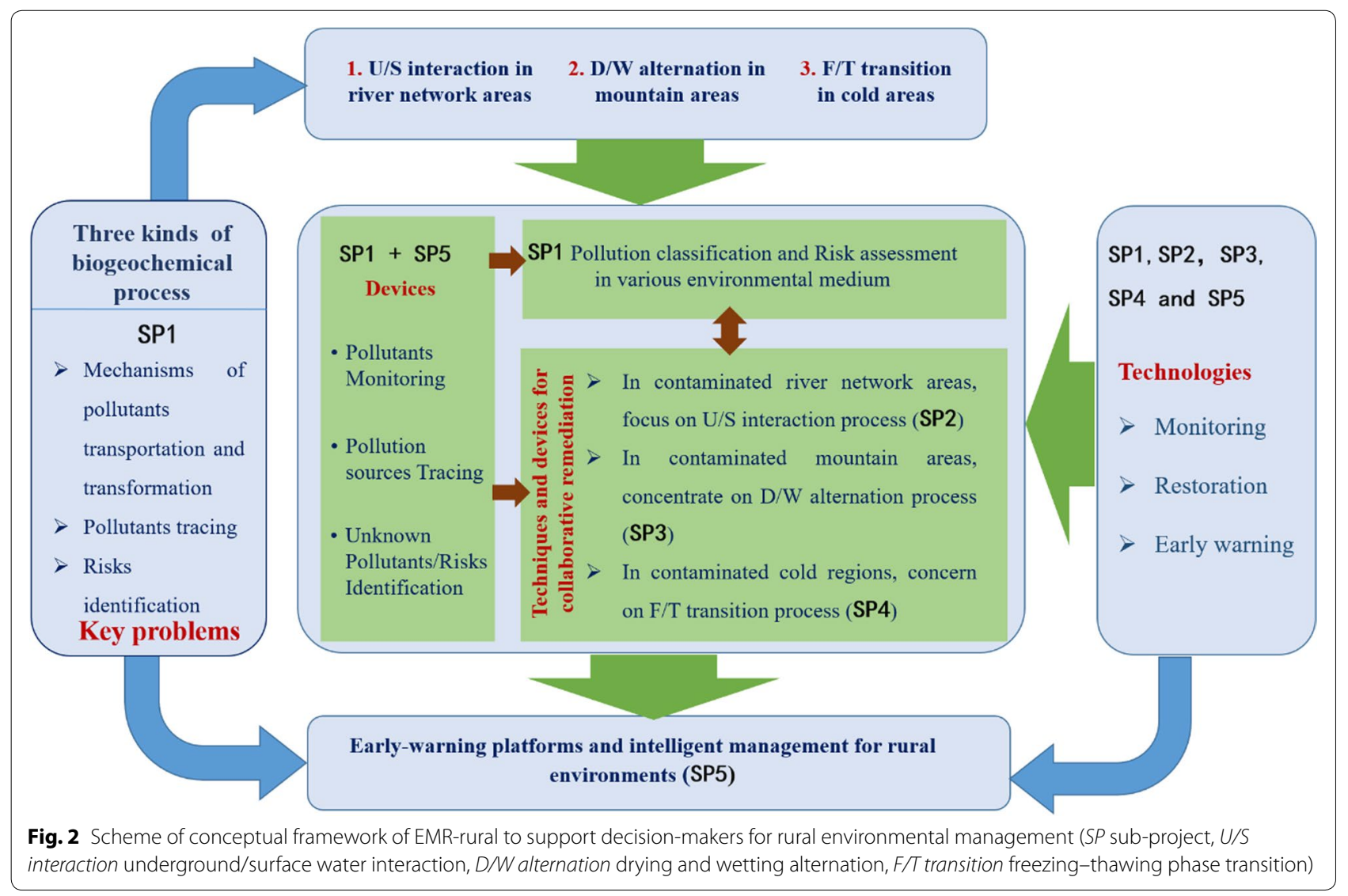


environmental factors on monitoring and supervision, including spectral tracing of pollution sources, environmental risk evaluation with multiple toxic endpoints' investigation, key toxicant pollutants' identification with non-target analysis, and risk screening biosensors' development. Based on the requirements of automated operation, integrative information, intelligent regulation and low maintenance of rural environment management, a monitoring station combining different kinds of sensors will be served to a platform to realize environmental supervision locally. These major products will support an early-warning management platform serving for pollution classification, risk assessment, and environmental monitoring at county scale.

In summary, the outcomes of SP1 on the fate of pollutants in three typical environmental processes (U/S interaction, $\mathrm{D} / \mathrm{W}$ alternation and $\mathrm{F} / \mathrm{T}$ transition) will provide basic environmental information and directions for the implementation of the other four sub-projects. The work of SP5 reflects on the SP1 regarding the pollution characteristics and pollutant fate by developing equipment for pollutants' tracing, techniques for unknown contamination identification and integrative system for environmental monitoring and pollution early-warning. SP5 simultaneously supports SP2, SP3 and SP4 to monitor environmental status during/after remediation, and to deepen the precision of technology development. Conversely, SP2, SP3, and SP4 will verify and reflect the theoretical methods and detecting techniques presented in SP1 and SP5. EMR-rural is expected to provide environmental status of specific pollutants in different river basins or regions, and to assist abatement options in rural.

\section{Approach}

Mechanism explanation with multi-disciplinary integration In consideration of the complexity of environments, EMR-rural will apply interdisciplinary and methodological knowledge to elucidate the interfacial behaviors, transportation and transformation of pollutants in water and soil during $\mathrm{U} / \mathrm{S}$ interaction, $\mathrm{D} / \mathrm{W}$ alternation and $\mathrm{F} / \mathrm{T}$ transition processes. Because environmental problems originate from a wide variety of sources (natural and man-made) and occur in various forms including biological, chemical, particulate or even energy. To parse pollution mechanism, studies must be done with different aspects, from understanding how the environment has evolved and how it functions, to the direct and indirect interactions [37]. Thus, the in situ pollution investigation, literature research, data analysis, and expert interviews will be integrated to expound characteristics of pollutants' distribution and transport flux. The project will make multivariate approaches to explain pollution mechanisms regarding source-sink conversion, essential transformation processes, and regulation principles in rural environments.

\section{Pilot studies for remediation techniques' exploration}

Pilot studies are preliminary studies that are often carried out before large-scale quantitative research, in an attempt to avoid time and money being used on an inadequately designed project [38]. Due to the uncertainty and the large number of associated variables in field implementation, pilot studies are frequently applied to evaluate the feasibility, adverse events, and improve upon the study design before a full-scale research project [39]. In particular for environmental remediation, a pilot study can serve as an effective screening tool in efficiency evaluation, approaches selection and process designing [40]. EMR-rural will construct three types of pilot systems to explore and evaluate remediation techniques and equipment. Three typical processes (U/S interaction, D/W alternation and $\mathrm{F} / \mathrm{T}$ transition) will be settled in pilot systems to simulate natural conditions in river-network region, mountainous region, and cold region, respectively. Pilot studies in EMR-rural will hence take on the responsibility to verify the transportation and transformation mechanisms of pollutants in rural environments. They are particularly important for the effective remediation approach development. In addition, in view of the advantage of pilot experiments on providing large amount of initial information, pilot studies will be applied to evaluate the efficiency of remediation techniques, and to collect technical parameters for optimization of fieldscale remediation [9]. Finally, the results of pilot study will be combined with the theoretical analysis of technology process and pollutants' characteristics to explore economical, applicable, and easy-to-handle techniques and equipment for rural environment remediation.

\section{Spectrum or biosensor-based portable detectors' development}

Spectrum technology has been intensely used in recent decades in the water quality monitoring programs for the dissolved organic matter analysis in water to evaluate the quality of various aquatic environments, such as sewage [41], oil [42] or pesticides [42]. Due to the capabilities of fluorescence spectroscopy, it has been suggested for pollution source identification [43]; while the in situ fluorescence experiments have been trapped to the limitation of proper portable instrumentation [44]. Moreover, the fixed excitation and emission wavelengths allow only the measurement of the specific chemicals [44]. EMRrural will develop a portable dual-mode spectral detector based on concave flat-field raster and array photoelectric coupling technology with the technique of pollution 
source tracing and the full-spectrum-based multi-parameter probe. A special dual-mode chemical reagent which is prepared according to the principle of chromogenic reaction and precipitation reaction will be applied in this detector. Afterward, the observed data will be analyzed by convolutional artificial neural network algorithms. According to the spectral database that obtained by the extensive investigation of rural samples, we can rapidly and accurately detect the rural-specific pollutants and trace the pollution sources.

As required by environmental monitoring programs, the portability, applicability and economics of detecting devices for a wide range of pollutants are essential for rural environment managements. The chemical sensors-based measuring devices are frequently applied in environmental detection with optical and/or electrochemical transduction [45]; for instance, volatile organic compounds' sensors [46], heavy metal ion sensors [47, 48], and pesticide and residual pesticide sensors [49]. These devices could only be optimized to interact with a specific analysis, which may not be appropriate for complex rural environment monitoring. While biosensors measure or monitor the occurrences of substances with the response of bio-materials, which provides the possibility on measuring pollutants in complex matrices with minimal sample preparation [50]. These methods have been hence encouraged for environmental mixture quality assessment [51]. EMR-rural will develop a biosensor integrated with a nuclear receptor affinity column for endocrine-disrupting effects' investigation and endocrine-disrupting compounds' identification, which could purify risk chemicals and test biological activity simultaneously.

\section{Effect-directed analysis (EDA) for unknown pollutants' identification}

Most environmental quality standards are established to address risk priority chemicals and other specific pollutants in monitoring programs. While the targeted chemical monitoring only for priority/specific chemicals cannot account for the presence of unknown chemicals and their transformation products [52]. Besides, environmental chemicals which are presented below guideline/standard values may still induce significant toxic effects since they are actually existed as mixtures in environments [53]. Numerous studies have indicated that substanceby-substance environmental monitoring could not reveal the real environmental effects, and target chemical analysis alone may lead to environmental pollution underestimation [54]. Effect-directed analysis (EDA) combines bioassays, fractionation and chemical analysis to identify bioactive chemicals in complex mixtures, which is designed to meet the challenge of reducing mixture complexity. EMR-rural will apply EDA for unknown pollutants' identification in rural water and soil/sediment samples. EMR-rural will start with biotesting for environmental organic extracts. If significant effects are detected, the complexity of the environmental sample is sequentially reduced by fractionation. Finally, the isolated toxic fractions are subjected to high-resolution mass spectrometry for key toxicants' identification [55].

\section{Field demonstration}

Numerous studies show that in situ works always fail when they equipped with new techniques or devices, even they have been successfully applied in both labscale and pilot-scale experiments. Field demonstration is necessary and particularly important, since it combined the complexity of in situ environments that are difficult to simulate and cover in laboratory. Thus, field demonstration will follow the lab experiments and pilot studies to validate the monitoring and remediation techniques and devices in EMR-rural. In consideration of the distinction of natural climate conditions and hydrological characteristics in different areas, field demonstration will be implemented in river network areas, mountainous regions and cold areas, respectively. To obtain applicable monitoring and remediation techniques in rural, technical parameters and processes' combinations will be optimized through demonstration. In addition, an intelligent monitoring platform, which equipped with pollution detection, classification, tracing and restoration, will be involved. This platform will take into consideration of the complexity of environmental medium and natural biogeochemical processes to form an environmental restoration system that is suitable for different spatial scales.

\section{Conclusion}

Given the goals of "the green livable village" construction, EMR-rural will provide techniques and devices for environmental monitoring and remediation with regard to soil, and underground and surface water quality in rural area. Based on the multi-disciplinary integration studies, in situ investigation, lab/pilot-scale experiment will be combined with field determination in EMR-rural to develop applicable tools for complex rural environments. This project will not only benefit to address the urgent rural environment problems, but also serve for the construction of rural revitalization and eco-environment improvement.

\section{Abbreviations}

EMR-rural: Environmental monitoring and remediation in rural project; PRA: Participatory rural appraisal; WWP: Working with people; IIRR: International Institute of Rural Reconstruction; CTA: Technical Center for Agricultural and Rural Cooperation; USDA: United States Department of Agriculture; ENRD: Office of Rural Development and European Network for Rural Development; 
MOST: Ministry of Science and Technology of the People's Republic of China; MARA: Ministry of Agriculture and Rural Affairs of the People's Republic of China; CAS: Chinese Academy of Sciences; PPCPs: Pharmaceutical and personal care products; PCBs: Polychlorinated biphenyls; PAHs: Polycyclic aromatic hydrocarbons; U/S interaction: Underground/surface water interaction; D/W alternation: Alternation of drying and wetting; F/T transition: Freezing-thawing phase transition; SP: Sub-project; EDA: Effect-directed analysis.

\section{Acknowledgements}

We appreciate the contribution for all participants.

\section{Authors' contributions}

JGS was responsible for the general design of the review and wrote the first draft of the manuscript. ZLC, FF and YS drafted the manuscript; JLL and YXJ supported data interpretation; YYW, MHZ, ZQG and MH contributed to supported the writing of the manuscript. All authors read and approved the final manuscript.

\section{Funding}

This work was supported by the National Key R\&D Program of China (No: 2019YFD1 100500), the National Natural Science Foundation of China (No. 51909015) and the Fundamental Research Funds for the Central Universities (Nos. 2019CDCGHS310 and 2019CDYGYB028).

\section{Availability of data and materials}

The datasets used and/or analyzed during the current study are available from the corresponding author on reasonable request.

\section{Ethics approval and consent to participate}

Not applicable.

\section{Consent for publication}

All authors agreed to publish the paper.

\section{Competing interests}

The authors declare that they have no competing interests.

\section{Author details}

${ }^{1}$ Key Laboratory of the Three Gorges Reservoir Region's Eco-Environment, College of Environment and Ecology, Chongqing University, Chongqing 400030, People's Republic of China. ${ }^{2}$ Environmental Simulate and Pollution Control State Key Joint Laboratory, Department of Environment Science and Engineering, Tsinghua University, Beijing 100084, People's Republic of China. ${ }^{3}$ State Key Laboratory of Pollution Control and Resources Reuse, Shanghai Institute of Pollution Control and Ecological Security, College of Environmental Science and Engineering, Tongji University, Siping Road, Shanghai 200092, People's Republic of China. ${ }^{4}$ Key Laboratory of Mountain Surface Processes and Ecological Regulation, Institute of Mountain Hazards and Environment, Chinese Academy of Sciences, Chengdu 610041, People's Republic of China. ${ }^{5}$ Key Laboratory of Pollution Ecology and Environmental Engineering, Institute of Applied Ecology, Chinese Academy of Sciences, Shenyang 110016, People's Republic of China.

Received: 15 February 2020 Accepted: 23 April 2020

Published online: 07 May 2020

\section{References}

1. Ellis F, Biggs S (2001) Evolving themes in rural development 1950s-2000s. Dev Policy Rev 19(4):437-448

2. Antrop M (2004) Landscape change and the urbanization process in Europe. Landsc Urban Plan 67(1):9-26

3. Yu ATW, Wu Y, Zheng B, Zhang X, Shen L (2014) Identifying risk factors of urban-rural conflict in urbanization: a case of China. Habitat Int 44:177-185

4. OECD. Regional development-Rural Development. 2002. http://www. oecd.org/governance/regional-policy/ruraldevelopment.htm

5. Goals DfSD (2008) A/RES/70/1 — transforming our world: the 2030 Agenda for Sustainable Development
6. Walker DH (2002) Decision support, learning and rural resource management. Agric Syst 73(1):113-127

7. Cazorla A, De Los Ríos I, Salvo M (2013) Working with people (WWP) in rural development projects: a proposal from social learning. Cuadernos de desarrollo Rural 10(SPE70):131-157

8. Chigbu UE (2012) Village renewal as an instrument of rural development: evidence from Weyarn, Germany. Community Dev 43(2):209-224

9. Vlist MJVD (1998) Land use planning in the Netherlands; finding a balance between rural development and protection of the environment. Landsc Urban Plan 41(2):135-144

10. Dufumier M (1992) Environment and rural development. Tiers Monde 33(130):295-310

11. Marsden T, Banks J, Renting H, Van Der Ploeg JD (2001) The road towards sustainable rural development: issues of theory, policy and research practice. J Environ Plan Policy Manage 3(2):75-83

12. Pašakarnis $G$, Maliene V (2010) Towards sustainable rural development in Central and Eastern Europe: applying land consolidation. Land Use Policy 27(2):545-549

13. Wang C, Yang Y, Zhang Y (2011) Economic development, rural livelihoods, and ecological restoration: evidence from China. AMBIO 40(1):78-87

14. Abrams JB, Gosnell H, Gill NJ, Klepeis PJ (2012) Re-creating the rural, reconstructing nature: an international literature review of the environmental implications of amenity migration. Conserv Soc 10(3):270-284

15. Bhagirath B, Reddy VR (2002) Environment and accountability: impact of industrial pollution on rural communities. Econ Polit Wkly 37(3):257-265

16. Ongley ED, Xiaolan Z, Tao Y (2010) Current status of agricultural and rural non-point source Pollution assessment in China. Environ Pollut 158(5):1159-1168

17. Withers PJA, Neal C, Jarvie HP, Doody DG (2014) Agriculture and eutrophication: where do we go from here? Sustainability 6(9):5853-5875

18. Guo P, Yokoyama K, Suenaga M, Kida H (2008) Mortality and life expectancy of Yokkaichi asthma patients, Japan: late effects of air pollution in 1960-70s. Environ Health 7:8

19. van Gaans PFM, Vriend SP, Bleyerveld S, Schrage G, Vos A (1995) Assessing environmental soil quality in rural areas. Environ Monit Assess 34(1):73-102

20. Su Y, Qi Y, Xiao Z, Wei Y (2009) Contributing institutional factors of rural environmental pollution in the process of modernization in China-in the perspective of the efficiency of environmental management system. Front Environ Sci Eng China 3(1):75-90

21. Chunmei W, Zhaolan L (2010) Environmental policies in China over the past 10 years: progress, problems and prospects. Procedia Environ Sci 2:1701-1712

22. McBeth MK, Foster RH (1994) Rural environmental attitudes. Environ Manage 18(3):401-411

23. Guéguen F, Stille P, Millet M (2011) Air quality assessment by tree bark biomonitoring in urban, industrial and rural environments of the Rhine Valley: PCDD/Fs, PCBs and trace metal evidence. Chemosphere 85(2):195-202

24. Bo L, Wang D, LiT, Li Y, Zhang G, Wang C, Zhang S (2015) Accumulation and risk assessment of heavy metals in water, sediments, and aquatic organisms in rural rivers in the Taihu Lake region, China. Environ Sci Pollut Res 22(9):6721-6731

25. Chagnon M, Kreutzweiser D, Mitchell EA, Morrissey CA, Noome DA, Van der Sluiijs JP (2015) Risks of large-scale use of systemic insecticides to ecosystem functioning and services. Environ Sci Pollut Res Int 22(1):119-134

26. Hendryx M, Fedorko E, Halverson J (2010) Pollution sources and mortality rates across rural-urban areas in the United States. J Rural Health 26(4):383-391

27. Gavrilescu M, Demnerová K, Aamand J, Agathos S, Fava F (2015) Emerging pollutants in the environment: present and future challenges in biomonitoring, ecological risks and bioremediation. New Biotechnol 32(1):147-156

28. Liu J-L, Wong M-H (2013) Pharmaceuticals and personal care products (PPCPS): a review on environmental contamination in China. Environ Int 59:208-224

29. Han D, Currell MJ, Cao G (2016) Deep challenges for China's war on water pollution. Environ Pollut 218:1222-1233

30. Persson LM, Breitholtz M, Cousins IT, de Wit CA, MacLeod M, McLachlan MS (2013) Confronting unknown planetary boundary threats from chemical pollution. Environ Sci Technol 47(22):12619-12622 
31. Geissen V, Mol H, Klumpp E, Umlauf G, Nadal M, van der Ploeg M, van de Zee SEATM, Ritsema CJ (2015) Emerging pollutants in the environment: a challenge for water resource management. Int Soil Water Conserv Res 3(1):57-65

32. Tilt B (2013) Industrial pollution and environmental health in rural China: risk, uncertainty and individualization. China Q 214:283-301

33. Qiu L, Dong Z, Sun H, Li H, Chang C-C (2016) Emerging pollutants_Part I: occurrence, fate and transport. Water Environ Res 88(10):1855-1875

34. Rodriguez-Mozaz S, Alda MJLd, Marco M-P, Barceló D (2005) Biosensors for environmental monitoring: a global perspective. Talanta 65(2):291-297

35. Othman MF, Shazali K (2012) Wireless sensor network applications: a study in environment monitoring system. Procedia Eng 41:1204-1210

36. Nizzetto L, Macleod M, Borgå K, Cabrerizo A, Dachs J, Guardo AD, Ghirardello D, Hansen KM, Jarvis A, Lindroth A, Ludwig B, Monteith D, Perlinger JA, Scheringer M, Schwendenmann L, Semple KT, Wick LY, Zhang G, Jones KC (2010) Past, present, and future controls on levels of persistent organic pollutants in the global environment. Environ Sci Technol 44(17):6526-6531

37. ENGINEERIN CAOSA (2000) The science of environmental pollution: a multi-disciplinary approach. Highlights Sci Technol Connecticut 4:1-15

38. Wikipedia. Pilot experiment. 2019. https://en.wikipedia.org/wiki/Pilot experiment

39. Thabane L, Ma J, Chu R, Cheng J, Ismaila A, Rios LP, Robson R, Thabane M, Giangregorio L, Goldsmith CH (2010) A tutorial on pilot studies: the what, why and how. BMC Med Res Methodol 10(1):1

40. Billé R (2010) Action without change? On the use and usefulness of pilot experiments in environmental management. SAPI EN. S. Surveys and perspectives integrating environment and society. (3.1)

41. Baker A (2001) Fluorescence excitation-emission matrix characterization of some sewage-impacted rivers. Environ Sci Technol 35(5):948-953

42. Bugden JBC, Yeung CW, Kepkay PE, Lee K (2008) Application of ultraviolet fluorometry and excitation-emission matrix spectroscopy (EEMS) to fingerprint oil and chemically dispersed oil in seawater. Mar Pollut Bul 56(4):677-685

43. Bieroza M, Baker A, Bridgeman J (2009) Relating freshwater organic matter fluorescence to organic carbon removal efficiency in drinking water treatment. Sci Total Environ 407(5):1765-1774

44. Carstea EM, Baker A, Bieroza M, Reynolds D (2010) Continuous fluorescence excitation-emission matrix monitoring of river organic matter. Water Res 44(18):5356-5366

45. Lieberzeit PA, Dickert FL (2007) Sensor technology and its application in environmental analysis. Anal Bioanal Chem 387(1):237-247

46. Steffens C, Leite FL, Manzoli A, Sandoval RD, Fatibello O, Herrmann PSP (2014) Microcantilever sensors coated with a sensitive polyaniline layer for detecting volatile organic compounds. J Nanosci Nanotechnol 14(9):6718-6722

47. Sivan V, Tang SY, O'Mullane AP, Petersen P, Eshtiaghi N, Kalantar-zadeh K, Mitchell A (2012) IEEE, enhanced electrochemical heavy metal ion sensor using liquid metal marbles_-towards on-chip application. In: 2012 conference on optoelectronic and microelectronic materials and devices. p 213

48. Sun P, Chen Y, Gao C, Liu X, Yang X, Xu M (2019) Heavy metal ion detection on a surface plasmatic resonance based on the change of refractive index. In: Jiang Y, Ma X, Li X, Pu M, Feng X, Kippelen B (eds) 9th international symposium on advanced optical manufacturing and testing technologies: optoelectronic materials and devices for sensing and imaging

49. Yan X, Li HX, Su XG (2018) Review of optical sensors for pesticides. TrAC, Trends Anal Chem 103:1-20

50. Lívia Maria da Costa Silva AFMAMS (2011) Biosensors for environmental applications. In: Somerset V (ed), InTech

51. Singh RP, Oh B-K, Koo K-K, Jyoung J-Y, Jeong S, Choi J-W (2008) Biosensor arrays for environmental pollutants detection. Biochip J 2(4):223-234

52. Escher BI, Ait-Aissa S, Behnisch PA, Brack W, Brion F, Brouwer A, Buchinger S, Crawford SE, Du Pasquier D, Hamers T, Hettwer K, Hilscherova K, Hollert $H$, Kase R, Kienle C, Tindall AJ, Tuerk J, van der Oost R, Vermeirssen E, Neale PA (2018) Effect-based trigger values for in vitro and in vivo bioassays performed on surface water extracts supporting the environmental quality standards (EQS) of the European Water Framework Directive. Sci Total Environ 628-629:748-765

53. Silva E, Rajapakse N, Kortenkamp A (2002) Something from "nothing" - eight weak estrogenic chemicals combined at concentrations below NOECs produce significant mixture effects. Environ Sci Technol 36(8):1751-1756

54. Shao Y, Xiao H, Di Paolo C, Deutschmann B, Brack W, Hollert H, Seiler TB (2019) Integrated zebrafish-based tests as an investigation strategy for water quality assessment. Water Res 150:252-260

55. Brack W, Ait-Aissa S, Burgess RM, Busch W, Creusot N, Di Paolo C, Escher Bl, Hewitt LM, Hilscherova K, Hollender J, Hollert H, Jonker W, Kool J, Lamoree M, Muschket M, Neumann S, Rostkowski P, Ruttkies C, Schollee J, Schymanski EL, Schulze T, Seiler T-B, Tindall AJ, Umbuzeiro GDA, Vrana B, Krauss M (2016) Effect-directed analysis supporting monitoring of aquatic environments - an in-depth overview. Sci Total Environ 544:1073-1118

\section{Publisher's Note}

Springer Nature remains neutral with regard to jurisdictional claims in published maps and institutional affiliations.

\section{Submit your manuscript to a SpringerOpen ${ }^{\circ}$ journal and benefit from:}

- Convenient online submission

- Rigorous peer review

- Open access: articles freely available online

- High visibility within the field

- Retaining the copyright to your article

Submit your next manuscript at $\boldsymbol{\nabla}$ springeropen.com 